\title{
Exploring the relationship between coping humor and subjective happiness: belongingness and forgiveness as serial mediators
}

BACKGROUND

Positive psychology plays an important role in strengthening mental health. Nevertheless, the relationships between variables have not been clarified yet. The present study used an undergraduate sample to test a mediation-based model of the cross-sectional association of coping humor with subjective happiness, as serially mediated by belongingness and forgiveness.

\section{PARTICIPANTS AND PROCEDURE}

A total of 306 valid participants $(51.6 \%$ female and $48.4 \%$ male), ranging in age from 18 to 26, completed paper and pencil questionnaires assessing subjective happiness, coping humor, belongingness, and forgiveness. The bootstrapping procedure was used for serial mediation.

\section{RESULTS}

The results indicated a significant and positive link among subjective happiness, coping humor, belongingness, and forgiveness. In addition, serial mediation analysis revealed that coping humor was associated with higher belongingness, which was associated with increased forgiveness, which were then associated with more subjective happiness. Therefore, coping humor was indirectly associated with more subjective happiness via belongingness and forgiveness, in a serial fashion.

\section{CONCLUSIONS}

These findings indicated that coping humor could help university students' belongingness, and improve forgiveness, thereby enhancing their subjective happiness. We suggest possible prevention and intervention programs for increasing subjective happiness among individuals with low coping humor and suggest courses for future inquiry. We also discuss the theoretical and practical implications of these findings.

\section{KEY WORDS}

subjective happiness; coping humor; belongingness; forgiveness; serial mediation

ORGANIZATION - Faculty of Education, Psychological Counseling and Guidance, Artvin Coruh University, Turkey AUthors' Contributions - A: Study design - B: Data collection - C: Statistical analysis - D: Data interpretation .

E: Manuscript preparation - F: Literature search - G: Funds collection

CORResponding AUthor - Begum Satici, Ph.D., Faculty of Education, Artvin Coruh University, Central Campus, 08000, Artvin, Turkey, e-mail: begum@artvin.edu.tr

TO CITE THIS ARTICLE - Satici, B. (2020). Exploring the relationship between coping humor and subjective happiness:

belongingness and forgiveness as serial mediators. Health Psychology Report, 8(3), 228-237. https://doi.org/10.5114/ hpr.2020.97329

RECEIVED 19.05.2020 - REVIEWED 29.06.2020 - ACCEPTED 30.06.2020 • PUBLISHED 24.07.2020 


\section{BACKGROUND}

Happiness or well-being has attracted the attention of philosophers, theologists, and psychologists for hundreds of years. Especially after the development of positive psychology, happiness has transformed into an attractive construct for all scientists as the focus is on constructs which strengthen the quality of life of individuals. Due to the nature of positive psychology, scientists have focused more on positive concepts than previously (Seligman, 2003). Happy individuals play a key role in positive psychology; they have better immune systems and physical health, they create more successful careers and even sleep better, they have lower suicide rates and may live longer (Larsen \& Eid, 2008; Lyubomirsky, King, \& Diener, 2005). In spite of happiness contributing so much to individuals, it is notable that some questions about it remain unanswered. For example, in spite of insufficient living conditions and many difficulties, some individuals may be happy, while some may describe themselves as unhappy even in the best situations (Lyubomirsky, 2001). Similarly, while some individuals are happy with even small things, others may find most good things are insufficient for happiness (Lyubomirsky, \& Lepper, 1999). In line with this, subjective happiness is encountered. Subjective happiness is defined as a subjective assessment of whether individuals are happy or unhappy (Lyubomirsky \& Tucker, 1998). As a result, the happiness concept may reveal the individual's subjective experiences and it may be an area effective in being strong individuals (Lyubomirsky \& Lepper, 1999).

A matter of curiosity is still how individuals can increase their subjective happiness which strengthens the quality of life; in other words, what are the determinants of subjective happiness? Coping humor which is one of the coping strategies when faced with difficult situations can predict subjective happiness. Herzog and Strevey (2008) found that individuals who use coping humor have increased happiness levels. Additionally, use of humor in a positive fashion is emphasized to make individuals feel happy (Yue, Liu, Jiang, \& Hiranandani, 2014). Similar findings about the relationship between humor and subjective happiness frequently appear in other research results (e.g., Chang et al., 2020; Ford, McCreight, \& Richardson, 2014; Yue, Hao, \& Goldman, 2010).

Previous studies have investigated the association of belongingness and forgiveness with subjective happiness. These researchers revealed that a feeling of belonging potentially leads to subjective happiness. Similarly, individuals who feel they belong experience social connectivity, which may elevate subjective happiness levels (Satıcı, Uysal, \& Deniz, 2016). Other studies have identified that those with strong belongingness do not feel lonely, obtain more satisfaction from their lives and are happy (e.g., Akdoğan \& Çimşir, 2019; Du \& Wei, 2015; Lee \& Robbins, 2000; Yoon, Hacker, Hewitt, Abrams, \& Cleary, 2012). In a similar way to belongingness, forgiveness is considered to be a construct strengthening the subjective happiness of individuals. Elemo, Satici, and Saricali (2018) pointed out that forgiveness directly increased the subjective happiness of young adults. Other research findings support the view that forgiveness is a positive predictor of subjective happiness (e.g., Datu, 2013; Vural-Batık, Bingöl, Kodaz, \& Hosoglu, 2017). As a result, it is proposed that belongingness and forgiveness have potential effects that strengthen subjective happiness.

In addition to all of this, research investigating complicated models of subjective humor among some people - especially young adults - is still limited. A recent study considered that subjective happiness will contribute to the network of relationships between coping humor, belongingness, and forgiveness. In conclusion, it appears logical that people using coping humor may have increased subjective happiness in their lives due to belongingness, and then forgiveness. As a result, in this cross-sectional study, we tested whether belongingness and forgiveness are serial mediators between coping humor and subjective happiness. The theoretical background of the model and logic are explained in detail in the following sections.

\section{COPING HUMOR AND SUBJECTIVE HAPPINESS}

Using humor, individuals may distance themselves from stressful or problematic situations (Lefcourt, 2001; Martin, Kuiper, Olinger, \& Dance, 1993) and thus humor contributes to the physical and psychological well-being of individuals (Martin, 2001). When individuals who use humor as a way of coping are faced with problems, they are said to imagine comic situations, make quips or jokes, and display comic behavior (Yerlikaya, 2009). Additionally, coping humor experienced during stressful events or a short while later can be used in a way to enjoy jokes and other entertaining forms of communication shared between individuals (Martin \& Ford, 2018).

Research indicates that using humor as a coping strategy may aid in reducing negative effects of exposure to negative events and situations in individuals' lives to a minimum (Abel, 2002; Chen \& Martin, 2007; Chang et al., 2020) and thus will strengthen subjective happiness. Supporting this research, an experimental study by Maiolino and Kuiper (2016) about the contribution of humor to well-being identified that brief humor exercises strengthened wellbeing. Additionally, college students using humor as a coping strategy were found to have increased
Coping humor, belongingness, forgiveness, subjective happiness 
subjective happiness levels (Chang et al., 2020) because individuals using coping humor experience nice feelings and obtain happiness from their situation. In fact, positive use of humor in life appears to increase subjective happiness levels (e.g., Ford et al., 2014; Páez, Seguel, \& Martınez-Sánchez, 2013; Yue et al., 2014). Therefore, the results of these studies indicate that coping humor will directly and positively predict the subjective happiness levels of young adults.

\section{BELONGINGNESS AND SUBJECTIVE HAPPINESS}

Adler (1927) stated that the feeling of belonging was a natural result of being human but that it was necessary to nourish and develop this feeling. Additionally, Maslow (1954) in a study aiming to understand what the needs of an individual comprise explained belonging as acceptance, recognition, assessment, and encouragement of a person by a group of people. As a result, individuals experiencing belongingness feel connectedness with their surroundings and these individuals may experience feelings which enhance the quality of life such as joy and satisfaction more often (Lee \& Robbins, 2000). Individuals without belongingness may be isolated from life and become more vulnerable to negative experiences such as anxiety, depression, and sadness (Hutcherson, Seppala, \& Gross, 2008).

When the literature is investigated, young adults without belongingness experiencing loneliness appear to have weakened subjective happiness (Akdoğan \& Çimşir, 2019). Another model study identified that college students experiencing belonging had directly elevated levels of subjective happiness (Satıcı et al., 2016). Longitudinal studies identified that those with strong belongingness obtained more satisfaction from life and were happy (Du \& Wei, 2015; Jose, Ryan, \& Pryor, 2012). Additionally, there are studies showing that strong social relationships related to belonging cause high levels of well-being, while weak social connections cause low levels of well-being (e.g., Appau, Churchill, \& Farrell, 2019). In addition, individuals forming close relationships with high belongingness are stated to be happier compared to those who do not form this type of relationship (e.g., Baumeister \& Leary, 1995; Liao \& Weng, 2018). As a result, belongingness is a basic human need and it can be concluded that it is a significant precondition for subjective happiness.

\section{FORGIVENESS AND SUBJECTIVE HAPPINESS}

Forgiveness may be defined as an internal and positive change shown by an individual who is wronged toward the guilty person (McCullough, Pargament, \& Thoresen, 2000) and involves renouncing feelings of revenge and anger toward the person (Thompson et al., 2005). The individual who forgives allows repair of the relationship disrupted by injustice by ensuring reconstruction of lost trust (Hargrave \& Sells, 1997); thus, the person who is wronged forgives and makes their own life more livable. Forgiving may save an individual from the effects of a negative event (McCullough, Worthington, \& Rachal, 1997) and they may attain the key to 'happiness and joy' (Friedman \& Toussaint, 2006).

Forgiving individuals have less anxiety, are more positive towards themselves and their surroundings and may have increased subjective happiness due to being free from pain. Previous studies supporting this view reported that forgiveness directly strengthened the happiness of college students (e.g., Datu, 2014; Osman \& Miranda, 2014; Vural Batık et al., 2017). For example, in a model study by Elemo et al. (2018), elevating levels of forgiveness of university students increased subjective happiness. Toussaint and Friedman (2008) supported this with findings of forgiveness positively predicting happiness. In fact, at the end of an experimental study including training about forgiveness, it was revealed that subjective happiness increased (Ramirez, Ortega, Chamorro, \& Colmenero, 2014). As a result, these studies indicate that forgiving generally has critical importance for happiness as it offers a greater contribution to achieving life satisfaction and desired mental health.

\section{AIM OF THE STUDY}

In the young adult period, individuals experience many stressors and conflicts in many areas such as interpersonal relationships, forming romantic relationships, ensuring academic progression and careers, etc. The responses given by individuals experiencing these situations are predicted to affect basic psychological development and happiness. Moving from this point, a multivariate model is required about how responses to possible stress and coping humor, belongingness, and forgiveness may shape the subjective happiness of young adults. Therefore, in this research the plan was to test a model including the relationships of coping humor, belongingness, and forgiveness with subjective happiness. Our hypothesized model is given in Figure 1. As seen above, research has dealt with the study variables in pairs; however, there was no study found revealing the serial aspects including all these variables. Additionally, studies present findings that coping humor may increase belongingness (e.g., Hickman \& Crossland, 2004; Meyer, 2000); belongingness may strengthen forgiveness (e.g., Barnes, Carvallo, 


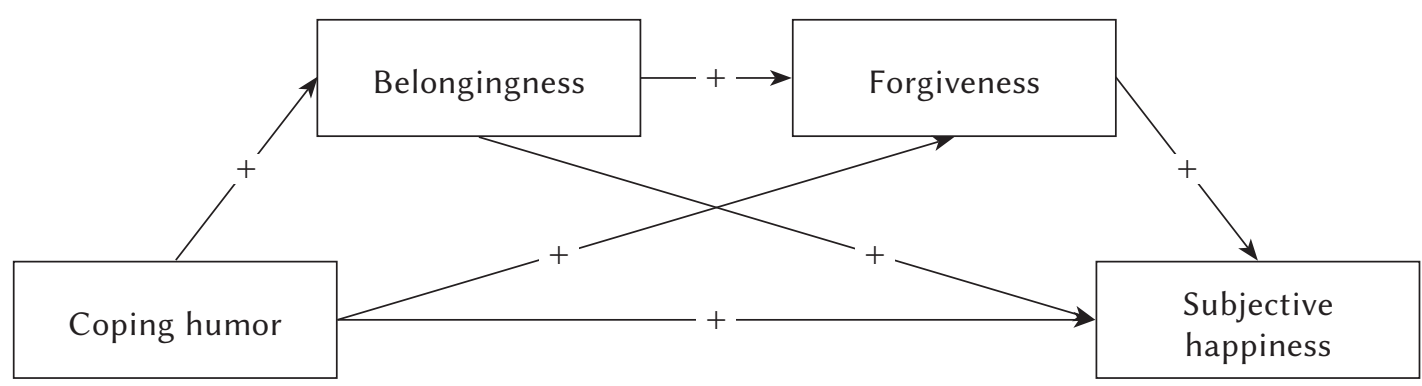

Figure 1. Hypothesized model.

Coping humor, belongingness, forgiveness, subjective happiness
Brown, \& Osterman, 2010; Exline, Baumeister, Bushman, Campbell, \& Finkel, 2004); and that forgiveness may elevate subjective happiness (e.g., Datu, 2014; Elemo et al., 2018; Osman \& Miranda, 2014). When examined in more detail, humor is a mechanism that may unite people by both strengthening connections and improving feelings of belonging to a group (Martin \& Ford, 2018). Additionally, Lefcourt (2001) stated that coping humor has a strengthening role in social connections. It is probable that people with strong belongingness have a tendency to forgive. In fact, individuals with high belonging see themselves as being close to those around them (Harber \& Wenberg, 2005) and may forgive them (McCullough, 2000). Additionally, Kayiş and Satici (2019) reported that forgiveness has a mediating role in the relationship between coping humor and happiness. As a result, based on all these research results and explanations, it is hypothesized that belongingness and forgiveness may have serial mediating roles in the relationship between coping humor and subjective happiness. Stated differently, cross-sectionally, the increase in coping humor levels will increase belongingness levels, increased belongingness will increase forgiveness levels and finally may increase subjective happiness.

\section{PARTICIPANTS AND PROCEDURE}

\section{PARTICIPANTS}

The study was completed with 306 students attending two different universities. The participants included 158 (51.6\%) females and 148 (48.4\%) males with mean age of 20.23 years $(S D=1.75$, age ranged from 18 to 26). When the students' fields of study were investigated, $124(40.5 \%)$ were studying educational sciences, 61 (19.9\%) literature, 40 (13.1\%) health science, 33 (10.8\%) engineering, and 30 (9.8\%) were studying management sciences. Eighteen $(5.9 \%)$ participants were outside these areas or did not report this information. In terms of perceived socioeconomic status, more than half of participants saw their socioeconomic status at moderate levels.
Table 1

Participants' characteristics $(N=306)$

\begin{tabular}{lc}
\hline Variables & $n(\%)$ \\
\hline Gender & \\
Female & $158(51.63)$ \\
Male & $148(48.37)$ \\
Current subject of study & \\
Education Sc. & $124(40.52)$ \\
Literary Sc. & $61(19.93)$ \\
Health Sc. & $40(13.07)$ \\
Engineering Sc. & $33(10.78)$ \\
Management Sc. & $30(9.80)$ \\
Other/not reported & $18(5.88)$
\end{tabular}

Perceived socio-economic status

Lowest

Lower-middle

Middle

Upper-middle

Highest

Age (mean $\pm \mathrm{SD})$ $20.23 \pm 1.75$

Detailed information about the participants is presented in Table 1.

\section{PROCEDURE}

Data were collected by self-administered paper and pencil questionnaires in a classroom environment. Participants were not given a reward in this study. All participants completed an informed consent form prior to their participation in the study. Moreover, verbal assent was obtained from participants before starting data collection. The procedure was in ac- 
cordance with the Helsinki Declaration. Also, this study was fully reviewed and approved by the Artvin Coruh University Scientific Research and Ethical Review Board (REF: 78646441-050.01.04-E.2700).

\section{MEASURES}

Subjective Happiness Scale. The Subjective Happiness Scale used to measure subjective happiness was developed by Lyubomirsky and Lepper (1999). The scale contains 4 items (e.g., "Compared with most of my peers, I consider myself”) and has 7-point Likert grading from 1 (less happy) to 7 (more happy). High points obtained on the scale emphasize increased levels of subjective happiness. The Turkish form of the scale was adapted by Akın and Satici (2011). The Turkish form was reported to be valid based on confirmatory factor analysis $(\mathrm{NFI}=.99, \mathrm{CFI}=1.00, \mathrm{RFI}=.98$, GFI $=1.00$, AGFI $=.99$ and SRMR $=.02)$ and reliable according to internal consistency $(\alpha=.86)$ results.

Coping Humor Scale. The Coping Scale used to measure coping humor was developed by Martin and Lefcourt (1983). The scale contains 7 items (e.g., "I can usually find something to laugh or joke about even in trying situations") and has 4-point Likert grading from 1 (strongly disagree) to 4 (strongly agree). High points obtained on the scale emphasize increased levels of coping humor. The Turkish form of the scale was adapted by Yerlikaya (2009). The criterion-dependent validity of the scale was tested in the Turkish adaptation study, had significant negative correlations with perceived stress, depression and state and trait anxiety and the internal consistency coefficient was reported to be 67 .

General Belongingness Scale. The General Belongingness Scale used to measure belongingness was developed by Malone, Pillow, and Osman (2012). The scale contains 12 items (e.g., "I have close bonds with family and friends") and has 7-point Likert grading from 1 (strongly disagree) and 7 (strongly agree). High points obtained on the scale emphasize increased levels of belongingness. The Turkish form of the scale was adapted by Satıcı and Tekin (2016). The Turkish form was reported to be valid based on confirmatory factor analysis $\left(\chi^{2}=129.36, \chi^{2} / d f=3.08, \mathrm{CFI}=.92\right.$, RMSEA $=.07$, SRMR $=.06$, GFI $=.93$, AGFI $=.90)$ and reliable according to internal consistency $(\alpha=.84)$ results.

Trait Forgiveness Scale. The Trait Forgiveness Scale used to measure forgiveness was developed by Berry, Worthington, O'Connor, Parrott, and Wade. The scale contains 10 items (e.g., "I can usually forgive and forget an insult") and has 5-point Likert grading from 1 (strongly disagree) to 5 (strongly agree). High points obtained on the scale emphasize increased levels of forgiveness. The Turkish form of the scale was adapted by Sarıcam and Akin (2013). The Turkish form was reported to be valid based on confirmatory factor analysis $\left(\chi^{2}=106.47, d f=32\right.$, RMSEA $=.08, \mathrm{CFI}=.89$, $\mathrm{GFI}=.95$, AGFI $=.91$, and SRMR $=.06)$ and reliable according to internal consistency $(\alpha=.67)$ results.

\section{DATA ANALYSIS}

To test the serial multiple mediation of belongingness and forgiveness between coping humor and subjective happiness, Model 6 within PROCESS v.3.2 developed as an SPSS macro by Hayes (2018) was used. Hayes provided findings about more than one parameter as a result of a single analysis in complicated models based on the regression-based bootstrapping technique using macros which are frequently studied and developing constantly. Within the scope of this study, the 10,000 bootstrap sample and bootstrap coefficient were removed and linked to this a $95 \%$ confidence interval was created. For acceptance of the results of these analyses as significant, it is necessary that the lower and upper limits of the confidence interval not include zero. It was concluded that as the lower and upper limits did not include zero, the direct and indirect effects were significant.

Model 6 was used to analyze serial multiple mediation models. In this regard, in Model 6, the direct and indirect effects of the independent variable of coping humor $(X)$ on the dependent variable of subjective happiness $(Y)$ were investigated, while at the same time the effect of the first mediator of belongingness $\left(M_{1}\right)$ via the second mediator of forgiveness $\left(M_{2}\right)$ on subjective happiness was dealt with. As a result, three separate nested mediation models of " $X \rightarrow$ $M_{1} \rightarrow Y$ ", " $X \rightarrow M_{2} \rightarrow Y$ " and " $X \rightarrow M_{1} \rightarrow M_{2} \rightarrow Y$ " can be tested in a single analysis. In mediation analysis, gender and age covariate variables were included in the model.

\section{RESULTS}

Before the mediation model, preliminary analyses investigated the reliability coefficients, mean, standard deviation, skewness and kurtosis coefficients for the variables. Additionally, the correlations between variables were evaluated. Findings related to preliminary analyses are presented in Table 2 .

All the variables appeared to have acceptable reliability coefficients. Additionally, it was found that the subjective happiness $(M=19.39, S D=4.32)$, coping humor $(M=16.88, S D=3.17)$, belongingness $(M=64.72, S D=10.83)$ and forgiveness $(M=31.09$, $S D=6.26)$ levels of participants were slightly above the relative means. In terms of skewness and kurtosis, all values met the assumptions of normal distribution. The results showed that all the variables were significantly correlated with each other. As antici- 
Table 2

Cronbach's $\alpha$, descriptive statistics, and correlations among studied variables

\begin{tabular}{lcccccccc}
\hline Variable & $\alpha$ & $M$ & $S D$ & Skewness & Kurtosis & 1 & 2 & 3 \\
\hline 1. Subjective happiness & .73 & 19.39 & 4.32 & -0.77 & 1.58 & - & & \\
2. Coping humor & .76 & 16.88 & 3.17 & 0.29 & 0.74 & $.39^{* * *}$ & - & \\
3. Belongingness & .83 & 64.72 & 10.83 & -1.09 & 1.79 & $.52^{* * *}$ & $.24^{* * *}$ & - \\
4. Forgiveness & .74 & 31.09 & 6.26 & -0.37 & 1.46 & $.51^{* * *}$ & $.33^{* * *}$ & $.49^{* * *}$ \\
\hline
\end{tabular}

Note. ${ }^{* * *} p<.001$

pated, subjective happiness was positively correlated with coping humor $(r=.39, p<.001)$, belongingness $(r=.52, p<.001)$, and forgiveness $(r=.51, p<.001)$. Coping humor was positively correlated with belongingness $(r=.24, p<.001)$ and forgiveness $(r=.33$, $p<.001)$.

\section{MEDIATION ANALYSES}

Figure 2 showed the path coefficients from the bootstrapped regression and mediation analyses for the effects of coping humor on subjective happiness through a sequential path of belongingness followed by forgiveness. Age and gender served as control variables in this model. The overall regression model examining the association between coping humor and subjective happiness was statistically significant, $R^{2}=.41, F(5,300)=41.16, p<.001$. Specifically, coping humor significantly predicted belongingness $(B=.24$, $S E=.18, p<.001)$, belongingness significantly predicted forgiveness $(B=.44, S E=.03, p<.001)$, and forgiveness significantly predicted subjective happiness $(B=.28, S E=.04, p<.001)$.
Table 3 presents the results of mediation analyses with coping humor as the independent variable, belongingness and forgiveness as the serial mediators, and subjective happiness as the dependent variable.

The bootstrap procedure revealed significant indirect effects between coping humor and subjective happiness with the mediating effect of belongingness $(b=.11, S E=.04, \mathrm{BC} 95 \% \mathrm{CI}=.04-.19)$ and forgiveness respectively $(b=.09, S E=.03, \mathrm{BC} 95 \% \mathrm{CI}=.04-.14)$. Moreover, there was significant serial mediation between coping humor and subjective happiness via increased belongingness and sequentially increased forgiveness $(b=.04, S E=.02, \mathrm{BC} 95 \% \mathrm{CI}=.01-.08)$.

\section{DISCUSSION}

Currently, for people to succeed, the required conditions are to survive and to maintain quality of life when faced with increasingly negative events. This research presents a model recommendation in order to identify determinants of subjective happiness. According to the research results, coping humor was determined to have a path directly increasing sub-
Coping humor, belongingness, forgiveness, subjective happiness

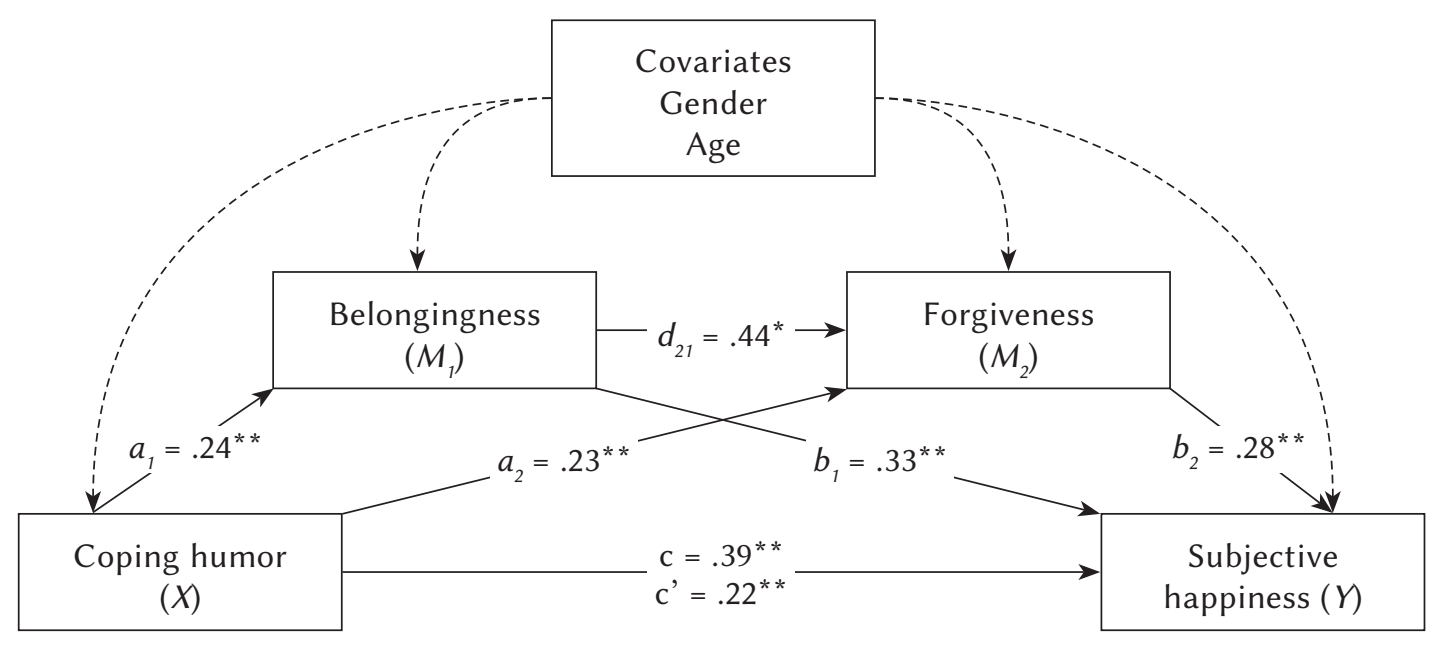

Figure 2. Serial-multiple mediation of belongingness and forgiveness in the association between coping humor and subjective happiness with standardized $\beta$ values and $p$-value. 
Table 3

Bootstrapping coefficients for the hypothesized model *

\begin{tabular}{|c|c|c|c|c|c|c|}
\hline Path & Effect & Boot LLCI & Boot ULCI & SE & $t$ & $p$ \\
\hline Total effect $(c)$ & .54 & .39 & .67 & .07 & 7.48 & $<.001$ \\
\hline Direct effect (c') & .30 & .17 & .43 & .06 & 4.63 & $<.001$ \\
\hline$a_{1}$ & .84 & .47 & 1.21 & .18 & 4.45 & $<.001$ \\
\hline$a_{2}$ & .45 & .25 & .64 & .10 & 4.52 & $<.001$ \\
\hline$b_{1}$ & .13 & .09 & .17 & .02 & 6.41 & $<.001$ \\
\hline$b_{2}$ & .19 & .12 & .26 & .04 & 5.21 & $<.001$ \\
\hline$d_{21}$ & .25 & .20 & .31 & .03 & 8.69 & $<.001$ \\
\hline \multicolumn{7}{|l|}{ Indirect effect } \\
\hline Total indirect effect & .24 & .12 & .37 & .06 & & \\
\hline$X \rightarrow M_{1} \rightarrow Y$ & .11 & .04 & .19 & .04 & & \\
\hline$X \rightarrow M_{2} \rightarrow Y$ & .09 & .04 & .14 & .03 & & \\
\hline$X \rightarrow M_{1} \rightarrow M_{2} \rightarrow Y$ & .04 & .01 & .08 & .02 & & \\
\hline
\end{tabular}

Note. Models include controls for gender and age. $L L C I$ lower limit confidence interval; ULCI upper limit confidence interval; $X$ - Coping humor; $M_{1}$ - belongingness; $M_{2}$ - forgiveness, $Y$ - subjective happiness, ${ }^{*}$ Unstandardized coefficients.

jective happiness. Additionally, with the increase in coping humor, the feeling of belongingness of individuals is strengthened and the tendency to forgive rises. It is understood that these increases and rises may also elevate subjective happiness.

The study identified three indirect effects; a) belongingness mediating the relationship between coping humor and subjective happiness, b) forgiveness mediating the relationship between coping humor and subjective happiness and c) the serial mediation by belongingness and forgiveness of the relationship between coping humor and subjective happiness. Coping humor is emphasized to save individuals from problematic situations experienced with those around them (Martin et al., 1993). Individuals who experience minimal problems with their surroundings may have an increased feeling of belonging to that environment because harmony is strengthened and they do not want to disconnect from the environment. Additionally, the use of humor as a coping mechanism increases sociocultural entrepreneurship (Lin, Li, \& Han, 2018) and thus belongingness may increase. Individuals with increased belonging due to coping humor may be less affected by negative situations in their surroundings and this will strengthen subjective happiness. This is because individuals experiencing belonging may feel emotions such as joy and satisfaction, which add to the quality of life, more frequently (Lee \& Robbins, 2000). Additionally, due to strengthened social bonds through the use of positive humor, individuals may obtain more satisfaction and may experience subjective happiness. As a result, in this study, the findings about the increase in subjective happiness due to belongingness and forgiveness which are both strengthened by coping humor can be said to support the relevant literature.

Humor is described as an effective method for coping with stressful or difficult situations (Chen \& Martin, 2007). Based on this description, it appears likely to increase the chance of forgiveness, a choice made after conflict and difficulty, because individuals with coping humor may more effectively manage conflict and stressful events in their lives (Rieger \& McGrail, 2013) and resolve these events more healthily. In fact, individuals using positive humor have a higher tendency toward forgiveness (Ramirez et al., 2014). Forgiving individuals are cleansed of pain and may think their lives are more livable, which may increase subjective happiness (Elemo et al., 2018). Additionally, individuals using humor as a coping strategy look at conflicts from a more positive perspective (Kuiper, McKenzie, \& Belanger, 1995), which may ease their ability to forgive and increase happiness. Another explanation is that individuals who use humor experience less anxiety, which allows them to view events more healthily (Marziali, McDonald, \& Donohue, 2008), and as a result this strengthens their tendency to forgive. Forgiving individuals feel better about themselves from a mental perspective, which may increase subjective happiness (Datu, 2014). Additionally, Kayiş and Satıc1 (2019) found that forgiveness mediated the relationship between coping humor and happiness. In 
conclusion, the findings of this study can be said to be consistent with and theoretically explained by the relevant literature.

The study also identified serial mediation between coping humor and subjective happiness by belongingness and forgiveness. Individuals may use humor as a form of coping to gain interpersonal or social rewards (Ford et al., 2014). Stated differently, humor is used to increase the quality, attractiveness and loyalty of social relationships. This use of humor will increase belonging. Belonging causes individuals to display forgiving attitudes (Exline et al., 2004) because individuals with high belonging see themselves as being closer to the people around them (Harber \& Wenberg, 2005). According to McCullough (2000), a feeling of closeness is an important determinant of forgiveness. Therefore, individuals without a feeling of belonging may be isolated from life and are known to experience more negative emotions such as anxiety, depression and sorrow, and this will progressively increase unhappiness (Hutcherson et al., 2008; Jose et al., 2012).

In addition to these explanations, there will be another discussion of the results occurring in this research. Coping humor appears to be a mechanism strengthening ties between individuals and reinforcing feelings of belonging (Martin \& Ford, 2018). As a result, individuals with low coping humor may have weakened connections to those around them and belonging will fall. With low belonging, in social life they may distance themselves from others and become increasingly lonely (Lee \& Robbins, 2000). With this loneliness, the negative aspects of life intensify and thoughts of experiencing injustice increase. Additionally, individuals with low belonging feel isolated, and rather than understanding the person opposite, they will begin to intensively think about how to fight against them (McCullough et al., 2000). Thus, individuals want other people to pay a price and do not entertain thoughts of forgiveness. As a result, with the reduction in forgiveness levels, it is considered that negative feelings in the lives of individuals will increase (Wuest, Ericson, Stern, \& Irwin, 2001). This prevents individuals from seeing positive events in their lives and will lower subjective happiness. In addition to all this, individuals who use humor and feel they belong to their social environment will chose the more virtuous behavior of forgiveness to sustain social relationships and thus may increase subjective happiness.

When interpreting the results of the study, it is beneficial to consider some limitations. Firstly, due to the cross-sectional nature of the study, it is difficult to identify causal connections between variables. The effect words mentioned in the study only represent a statistical association. To reveal effects in a real sense observed between variables, there is a need for longitudinal or experimental studies.
Secondly, there are the limitations of data being obtained from self-report scale tools. Though data were obtained from students who volunteered for the study, due to the limitations of self-report scale tools, participants may have provided biased responses. Additionally, the concepts in the study are limited by the scope of self-report scale tools. It is recommended that future studies should investigate with a method allowing multiple dimensions of the concepts to be considered.

\section{CONCLUSIONS}

Along with these limitations, the importance of the study should not be ignored. This study, dealing with coping humor, belongingness, forgiveness and subjective happiness together for the first time, revealed connections between variables. In the young adult period when stress is due to countless different sources, this study provides information about what results occur when as one of the responses to this stress coping humor is used. In situations where coping humor is used, young adults feel they belong to their surroundings more and this feeling of belongingness supports their entertaining forgiving tendencies. Strengthening belongingness and forgiveness was revealed to lead to an increase in subjective happiness levels, an important value in the determination of quality of life.

\section{References}

Abel, M. H. (2002). Humor, stress, and coping strategies. Humor: International Journal of Humor Research, 15, 365-381.

Adler, A. (1927). Understanding Human Nature. New York: Garden City Publishing Company, Inc.

Akdoğan, R., \& Çimşir, E. (2019). Linking inferiority feelings to subjective happiness: Self-concealment and loneliness as serial mediators. Personality and Individual Differences, 149, 14-20.

Akin, A., \& Satici, S. A. (2011). Subjective Happiness Scale: A study of validity and reliability. Sakarya University Journal of Education Faculty, 21, 65-77.

Appau, S., Churchill, S. A., \& Farrell, L. (2019). Social integration and subjective wellbeing. Applied Economics, 51, 1748-1761. https://doi.org/10.1080/000 36846.2018.1528340

Barnes, C. D., Carvallo, M., Brown, R. P., \& Osterman, L. (2010). Forgiveness and the need to belong. Personality and Social Psychology Bulletin, 36, 1148-1160.

Baumeister, R. F., \& Leary, M. R. (1995). The need to belong: desire for interpersonal attachments as a fundamental human motivation. Psychological Bulletin, 117, 497-529.
Coping humor, belongingness, forgiveness, subjective happiness 
Berry, J. W., Worthington Jr, E. L., O’Connor, L. E., Parrott III, L., \& Wade, N. G. (2005). Forgivingness, vengeful rumination, and affective traits. Journal of Personality, 73, 183-226.

Chang, E. C., Yi, S., Liu, J., Kamble, S. V., Zhang, Y., Shi, B., ... \& Shen, J. (2020). Coping behaviors as predictors of hedonic well-being in Asian Indians: does being optimistic still make a difference? Journal of Happiness Studies, 21, 289-304.

Chen, G. H., \& Martin, R. A. (2007). A comparison of humor styles, coping humor, and mental health between Chinese and Canadian university students. Humor, 20, 215-234.

Datu, J. A. D. (2014). Forgiveness, gratitude and subjective well-being among Filipino adolescents. International Journal for the Advancement of Counselling, 36, 262-273.

Du, Y., \& Wei, M. (2015). Acculturation, enculturation, social connectedness, and subjective wellbeing among Chinese international students. The Counseling Psychologist, 43, 299-325.

Elemo, A. S., Satici, S. A., \& Saricali, M. (2018). Anger rumination and subjective happiness: forgiveness and vengeance as mediators. International Journal of Happiness and Development, 4, 147-158.

Exline, J. J., Baumeister, R. F., Bushman, B. J., Campbell, W. K., \& Finkel, E. J. (2004). Too proud to let go: narcissistic entitlement as a barrier to forgiveness. Journal of Personality and Social Psychology, 87, 894-912.

Ford, T. E., McCreight, K. A., \& Richardson, K. (2014). Affective style, humor styles and happiness. Europe's Journal of Psychology, 10, 451-463.

Friedman, P. H., \& Toussaint, L. L. (2006). The relationship between forgiveness, gratitude, distress, and well-being: An integrative review of the literature. International Journal of Healing and Caring, 6, 1-10.

Harber, K. D., \& Wenberg, K. E. (2005). Emotional disclosure and closeness toward offenders. Personality and Social Psychology Bulletin, 31, 734-746.

Hargrave, T. D., \& Sells, J. N. (1997). The development of a Forgiveness Scale. Journal of Marital and Family Therapy, 23, 41-62.

Hayes, A. F. (2018). Introduction to mediation, moderation, and conditional process analysis: A regressionbased approach. Guilford Publications: New York.

Herzog, T. R., \& Strevey, S. J. (2008). Contact with nature, sense of humor, and psychological wellbeing. Environment and Behavior, 40, 747-776.

Hickman, G. P., \& Crossland, G. L. (2004). The predictive nature of humor, authoritative parenting style, and academic achievement on indices of initial adjustment and commitment to college among college freshmen. Journal of College Student Retention: Research, Theory \& Practice, 6, 225-245.

Hutcherson, C. A., Seppala, E. M., \& Gross, J. J. (2008). Loving-kindness meditation increases social connectedness. Emotion, 8, 720-724.
Jose, P. E., Ryan, N., \& Pryor, J. (2012). Does social connectedness promote a greater sense of well-being in adolescence over time? Journal of Research on Adolescence, 22, 235-251.

Kayiş, A. R., \& Satici, S. A. (2019). The mediating role of forgiveness in the relationship between coping humor and mental well-being. Kastamonu Education Journal, 27, 1495-1504.

Kuiper, N. A., McKenzie, S. D., \& Belanger, K. A. (1995). Cognitive appraisals and individual differences in sense of humor: Motivational and affective implications. Personality and Individual Differences, 19, 359-372.

Larsen, R. J., \& Eid, M. (2008). Ed Diener and the science of SWB. In M. Eid \& R. J. Larsen (Eds.), The science of subjective well-being (pp. 1-16). New York, NY: Guilford Press.

Lee, R. M., \& Robbins, S. B. (2000). Understanding social connectedness in college women and men. Journal of Counseling \& Development, 78, 484-491. Lefcourt, H. M. (2001). Humor: The psychology of living buoyantly. New York: Springer.

Liao, K. Y. H., \& Weng, C. Y. (2018). Gratefulness and subjective well-being: Social connectedness and presence of meaning as mediators. Journal of Counseling Psychology, 65, 383-393.

Lin, S., Li, J., \& Han, R. (2018). Coping humor of entrepreneurs: Interaction between social culture and entrepreneurial experience. Frontiers in Psychology, 9, 1449.

Lyubomirsky, S. (2001). Why are some people happier than others? The role of cognitive and motivational process in well-being. American Psychologist, 56, 239-249.

Lyubomirsky, S., \& Lepper, H. S. (1999). A measure of subjective happiness: Preliminary reliability and construct validation. Social Indicators Research, 46, 137-155.

Lyubomirsky, S., \& Tucker, K. L. (1998). Implications of individual differences in subjective happiness for perceiving, interpreting, and thinking about life events. Motivation and Emotion, 22, 155-186.

Lyubomirsky, S., King, L., \& Diener, E. (2005). The benefits of frequent positive affect: Does happiness lead to success? Psychological Bulletin, 131, 803-855.

Maiolino, N., \& Kuiper, N. (2016). Examining the impact of a brief humor exercise on psychological well-being. Translational Issues in Psychological Science, 2, 4-13.

Malone, G. P., Pillow, D. R., \& Osman, A. (2012). The general belongingness scale (GBS): Assessing achieved belongingness. Personality and Individual Differences, 52, 311-316.

Martin, R. A. (2001). Humor, laughter, and physical health: methodological issues and research findings. Psychological Bulletin, 127, 504-519.

Martin, R. A., \& Ford, T. (2018). The psychology of humor: An integrative approach. London: Elsevier Academic Press. 
Martin, R. A., \& Lefcourt, H. M. (1983). Sense of humor as a moderator of the relation between stressors and moods. Journal of Personality and Social Psychology, 45, 1313-1324.

Martin, R. A., Kuiper, N. A., Olinger, L. J., \& Dance, K. A. (1993). Humor, coping with stress, self-concept, and psychological well-being. Humor: International Journal of Humor Research, 6, 89-104.

Marziali, E., McDonald, L., \& Donahue, P. (2008). The role of coping humor in the physical and mental health of older adults. Aging and Mental Health, 12, 713-718.

Maslow, A. H. (1954). Motıvation and Personality. New York: Harper \& Row, Publishers, Inc.

McCullough, M. E. (2000). Forgiveness as human strength: Theory, measurement, and links to wellbeing. Journal of Social and Clinical Psychology, 19, 43-55.

McCullough, M. E., Pargament, K. I., \& Thoresen, C. E. (Eds.). (2000). Forgiveness: Theory, research, and practice. New York: Guilford Press.

McCullough, M. E., Worthington Jr, E. L., \& Rachal, K. C. (1997). Interpersonal forgiving in close relationships. Journal of Personality and Social Psychology, 73, 321-336.

Meyer, J. C. (2000). Humor as a double-edged sword: Four functions of humor in communication. Communication Theory, 10, 310-331.

Osman, M., \& Miranda, D. (2014). Validation of a new measure of trait forgiveness: Multi-Systemic Forgiveness Scale (MSFS). Personality and Individual Differences, 60, S76-S77.

Páez, D., Seguel, A. M., \& Martínez-Sánchez, F. (2013). Incremental validity of alexithymia, emotional coping and humor style on happiness and psychological well-being. Journal of Happiness Studies, 14, 1621-1637.

Ramírez, E., Ortega, A. R., Chamorro, A., \& Colmenero, J. M. (2014). A program of positive intervention in the elderly: Memories, gratitude and forgiveness. Aging \& Mental Health, 18, 463-470.

Rieger, A., \& McGrail, J. P. (2013). Coping humor and family functioning in parents of children with disabilities. Rehabilitation Psychology, 58, 89-97.

Sarıcam, H., \& Akin, A. (2013). Affedicilik Ölçeğinin Türkçe formu: Geçerlik ve güvenirlik çalışması [Turkish Version of the Forgiveness Scale: Validity and Reliability Study]. HAYEF: Journal of Education, 10, 37-46.

Satici, S. A., \& Tekin, E. G. (2016). Psychometric properties of the general belongingness scale in Turkish youth. Current Psychology, 35, 625-631.

Satici, S. A., Uysal, R., \& Deniz, M. E. (2016). Linking social connectedness to loneliness: The mediating role of subjective happiness. Personality and Individual Differences, 97, 306-310.

Seligman, M. E. (2003). Fundamental assumptions. The Psychologist, 16, 126-127.
Thompson, L. Y., Snyder, C. R., Hoffman, L., Michael, S. T., Rasmussen, H. N., Billings, L. S., ... \& Roberts, D. E. (2005). Dispositional forgiveness of self, others, and situations. Journal of Personality, 73, 313-360.

Toussaint, L., \& Friedman, P. (2009). Forgiveness, gratitude, and well-being: The mediating role of affect and beliefs. Journal of Happiness Studies, 10, 635-654.

Vural-Batik, M., Bingöl, T. Y., Kodaz, A. F., \& Hosoglu, R. (2017). Forgiveness and Subjective Happiness of University Students. International Journal of Higher Education, 6, 149-162.

Wuest, J., Ericson, P. K., Stern, P. N., \& Irwin Jr, G. W. (2001). Connected and disconnected support: The impact on the caregiving process in Alzheimer's disease. Health Care for Women International, 22, 115-130.

Yerlikaya, E. E. (2009). The relationship between humor styles and perceived stress, anxiety and depression of college students. Unpublished Doctoral Dissertation, Cukurova University, Institute of Social Sciences, Adana.

Yoon, E., Hacker, J., Hewitt, A., Abrams, M., \& Cleary, S. (2012). Social connectedness, discrimination, and social status as mediators of acculturation/enculturation and well-being. Journal of Counseling Psychology, 59, 86-96.

Yue, X. D., Hao, X., \& Goldman, G. L. (2010). Humor styles, dispositional optimism, and mental health among undergraduates in Hong Kong and China. Journal of Psychology in Chinese Societies, 11, 173-188.

Yue, X. D., Liu, K. W. Y., Jiang, F., \& Hiranandani, N. A. (2014). Humor styles, self-esteem, and subjective happiness. Psychological Reports, 115, 517-525.
Coping humor, belongingness, forgiveness, subjective happiness 